\title{
Opensource Software for MLR-Modelling of Solar Collectors
}

\author{
Bacher, Peder; Perers, Bengt
}

Published in:

Proceedings of ISES Solar World Conference 2011

Publication date:

2011

Link back to DTU Orbit

Citation (APA):

Bacher, P., \& Perers, B. (2011). Opensource Software for MLR-Modelling of Solar Collectors. In Proceedings of ISES Solar World Conference 2011 http://www.swc2011.org/cms/

\section{General rights}

Copyright and moral rights for the publications made accessible in the public portal are retained by the authors and/or other copyright owners and it is a condition of accessing publications that users recognise and abide by the legal requirements associated with these rights.

- Users may download and print one copy of any publication from the public portal for the purpose of private study or research.

- You may not further distribute the material or use it for any profit-making activity or commercial gain

- You may freely distribute the URL identifying the publication in the public portal

If you believe that this document breaches copyright please contact us providing details, and we will remove access to the work immediately and investigate your claim. 


\title{
OPENSOURCE SOFTWARE FOR MLR-MODELLING OF SOLAR COLLECTORS
}

\author{
Peder Bacher \\ DTU Informatics, Richard Pedersens Plads, Building 321, DK-2800 Lyngby, Denmark \\ Bengt Perers \\ DTU Civil Engineering, Brovej, Building 118, DK-2800 Lyngby
}

\begin{abstract}
A first research version is now in operation of a software package for multiple linear regression (MLR) modeling and analysis of solar collectors according to ideas originating all the way from Walletun et. al. (1986), Perers, (1987 and 1993). The tool has been implemented in the free and open source program R http://www.r-project.org/. Applications of the software package includes: visual validation, resampling and conversion of data, collector performance testing analysis according to the European Standard EN 12975 (Fischer et al., 2004), statistical validation of results, and the determination of collector incidence angle modifiers without the need of a mathematical function (Perers, 1997). The paper gives a demonstration with examples of the applications, based on measurements obtained at a test site at DTU in Denmark (Fan et al., 2009). The tested collector is a single glazed large area flat plate collector with selective absorber and teflon anti convection layer.

The package is intended to enable fast and reliable validation of data, and provide a united implementation for MLR testing of solar collectors. This will furthermore make it simple to replicate the calculations by a third party in order to validate the results. Finally more advanced methods can be implemented and easily shared as extensions to the package, for example methods for statistical estimation of the incidence angle modifier with non-linear functions for collectors with more complicated optics.

The overall advantage of this kind of tool and analysis is that it is almost the inverse of simulation. Therefore the model and parameters will be very well validated for application in later use for system simulation, even if the test is no real system test. Also for annual collector performance calculations with a new Excel tool connected to EN 12975 (Kovacs, 2011) this built in validation gives an extra quality assurance.
\end{abstract}

\section{Introduction}

A large database is created during a normal solar collector test according to the EN12975 (2006) standard. To have a fast check and efficient evaluation of the data there is a need for a software that can run through the data quickly. Some of the steps are check and selection of OK data points, scaling of units and conversion of raw data to an appropriate MLR input form and finally statistically estimated collector parameters can be reported. When applying stationary testing (SS) a larger amount of data, has to be collected compared to a quasi dynamic test (QDT). But the number of data points finally used in the analysis to get the collector parameters is much larger in the QDT method. Therefore a fast and efficient evaluation tool is very desirable.

For the QDT method several parameter identification methods can be used. One of them is Multiple Linear Regression (MLR). In opposition to what you normally think, due to the word Linear, the collector model can still be highly nonlinear in the terms, when using MLR. Also stepwise identification using so called "dummy variables" can be applied to identify a parameter in different ranges of the database in the same run. This is for example very useful for collectors with an incidence angle behavior that can't be described with a simple mathematical function. A big advantage of the MLR method proposed in the QDT method is also that a time sequence of data without gaps is not needed. Therefore the deselection of data points due intermittent problems with for example the test rig, test object or sensors is no problem.

In Sweden an Excel tool has been developed at SP www.sp.se for the analysis of QDT test results. This is used for all kinds of collectors. When the database becomes large, and when highly asymmetric collectors are investigated, Excel has limitations in capacity and the first steps have been taken to develop an alternative tool using the open source statistical and graphical software "R" http://www.r-project.org/

Some of the ideas implemented here come from the period when the first steps towards the MLR/QDT method was taken and access to the Minitab statistical software was available. This work was done in connection to the IEA SH\&C Task III cooperation for collector and system testing. Walletun et. al. (1986), Perers, (1987 and 1993).

The overall advantage of this kind of tool and analysis is that it is almost the opposite of simulation so the model and parameters will be very well validated for application in later use for system simulation even if 
the test is no real system test. Also for standardized annual collector performance calculations with a newly developed Excel tool for EN 12975 Perers et. al. (2011) this built in validation in the QDT method and this tool gives an extra quality assurance.

The test design is also very important and should be a systematic emulator of all normal operating states for the collector in a real system, plus some extra extreme states of high and low operating temperature to separate the model parameters from each other.

This principle can be further improved in the EN12975 QDT method. The QDT method was very much restricted in the standard writing to also give stationary test (SS) data points in the same test period. Therefore a perfect constant inlet temperature was specified during all test days. In this respect the SS method is far from an all day model plus parameter validation, even if the model plus parameters are very well defined for clear sky conditions within a certain diffuse fraction range, that is the requirement during testing. The built in error due to varying diffuse fraction during an SS test, is quantified and a correction method is proposed in Kovacs et. al. (2011)

The proposed evaluation tool can be extended to also select and evaluate stationary collector test data if the test sequence is run according to the SS method. MLR is already applied to determine the stationary collector parameters and efficiency curve in an SS test, but in a limited form for only tree parameters.

\section{Description of the main parts of the tool}

The tool can be divided in a number of important steps from reading of raw data until final results.

1) Raw test data reading into the software

2) Input of collector parameters as Aperture area, Tilt and Orientation. Latitude and Longitude of the test site.

3) Organisation of the data in a standardized format including units for further analysis

4) Check of data and removing obviously wrong data points like negative solar radiaton, temperatures or other variables out of range. (This can be caused by power failures or repair of sensors or wires for example). Plots of raw data can be a very efficient check too to see strange or wrong values.

5) Creation of the collector model terms in a standardized way like the term (Tm-Ta) or (Tm-Ta $)^{2}$ or the dTf/Dt capacitance term. Note that the collector model terms are set up in output power form and not efficiency form so that the parameters set derived in the analysis will minimize the error in collector output power and not the error in efficiency like in the SS method.

6) Re-sampling from the time step in raw data like $30 \mathrm{sec}$ averages or $2 \mathrm{sec}$ instantaneous values to a time step suitable for the model analysis, normally 5-10 min averages, presently when using just a one node capacitance correction term.

7) Check of the cross correlation of the input series in the collector model to see that the requirement for independency is fulfilled and that the input variables like inlet temperature and incidence angles are varied enough during the test to achieve reliable parameter values. This is an often forgotten requirement not only for an MLR analysis. It is not possible to identify accurate and reliable parameters if for example the inlet temperature variations has been too limited like in most cases in system operation of a collector.

8) Selection of data according to specific rules in the standard or research requirements. It can be positive collector output, incidence angles smaller than $85 \mathrm{deg}$ or solar radiation greater than $50 \mathrm{~W} / \mathrm{m} 2$ for example.

9) Run the MLR routine. Check if the parameter values and statistical results are reasonable. For example the t-ratio should be greater than 2 to keep a parameter and term in the collector equation.

10) Plot of the statistical results and model output power versus measured output. Check for outliers that can indicate wrong data in some way. For example visitors shading the collector sample for some minutes unintentionally or a bird sitting on a solar sensor for some time. A lose wire or connector can also give intermittent measurement errors. There are many more examples in real testing life that has to be removed from data before accurate results can be achieved. In this step the $\mathrm{R}$ tool is very efficient in plotting the data and finding the strange points. Also the allowance in the MLR procedure to have data gaps when data has to be removed is very useful.

\section{Some examples of results from the MLR/QDT- $R$ tool}

Below are some diagrams showing results of an analysis of measurements on a large area flat plate collector at DTU, (Fan et. al. 2009). The test was done according to the SS method, but as different operating temperatures were present within the test period also the QDT and MLR method could be used to analyse data. In this case as it was a research test also data points during the night could be used to check the future 
possibilities to shorten the testing time, by varying the inlet temperature during night and estimate the heat loss parameters more accurately and faster.

Figure 1-3 gives all day and also night results showing that the analysis method gives a very good model fit to real measurements of collector output. Also some large fluctuations in inlet temperature and flow are shown to be handled well as rapid fluctuations in solar radiation.

Figure 4 gives an example of the option in the tool to determine the incidence angle modifier with statistical estimation of non-linear functions without the need of a simple mathematical function (black and red points). Also the separation of morning and afternoon values are shown to give an impression of the reproducibility that the method can give. As a comparison the standard b0 equation is shown for the same data set. It is interesting to note the cut off before 90 degrees that is caused by shading of the absorber from the frame of the collector. This detailed evaluation of the measurements, require a test rig and sensors in very good shape. Small errors will otherwise show up here like a test rig not oriented due south for example or bad adjustment or mounting of a shading ring or misalignment of solar sensors. Also other measurement problems or errors will show up and this is also one advantage with this tool that the quality of the test rig can be improved step by step based on this kind of results.

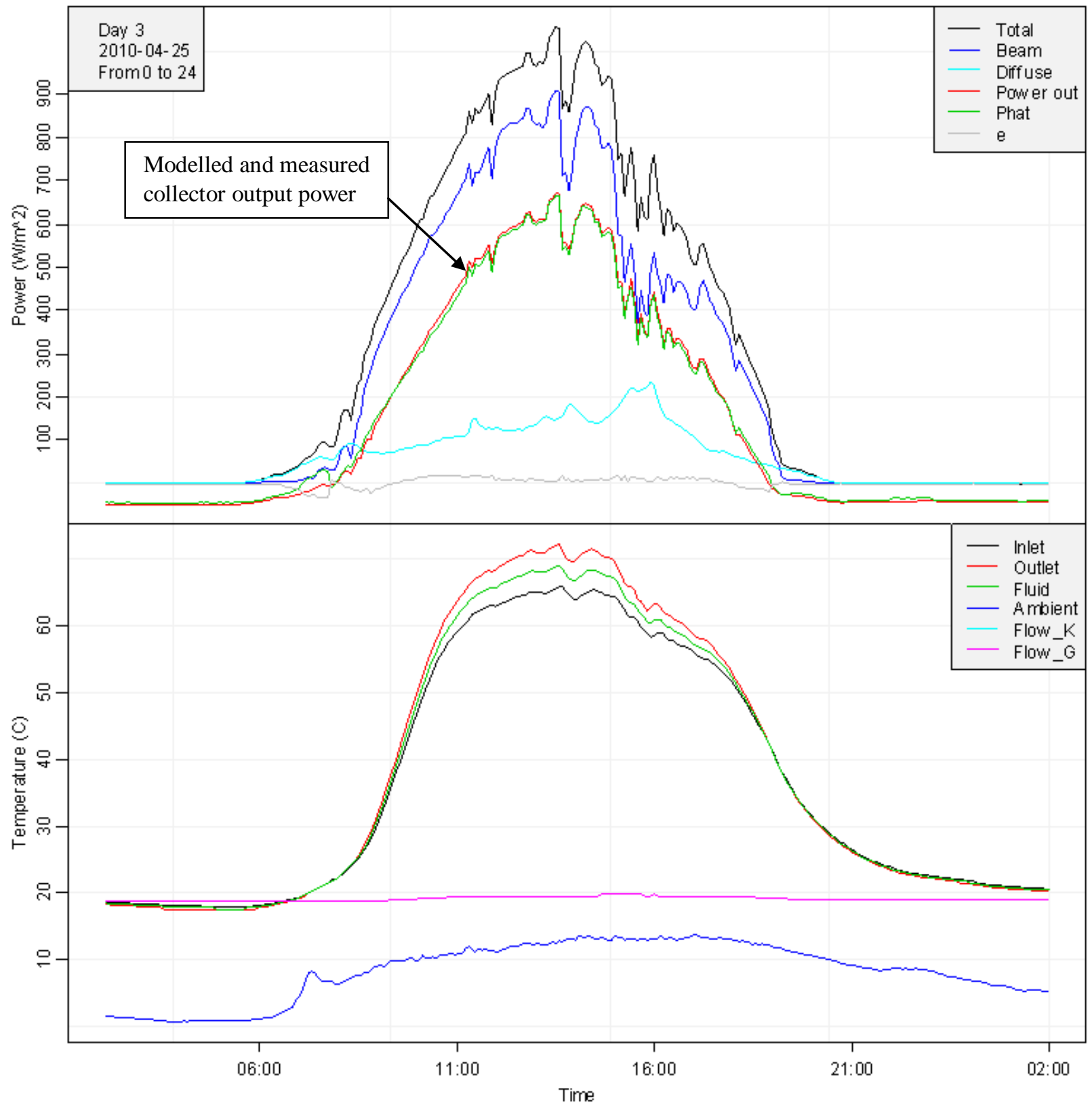

Fig. 1: All day measurements and validation of the method and model plus parameters. The red curve in the upper diagram is measured collector output and the green curve is the model output with the identified parameters for the whole test period 


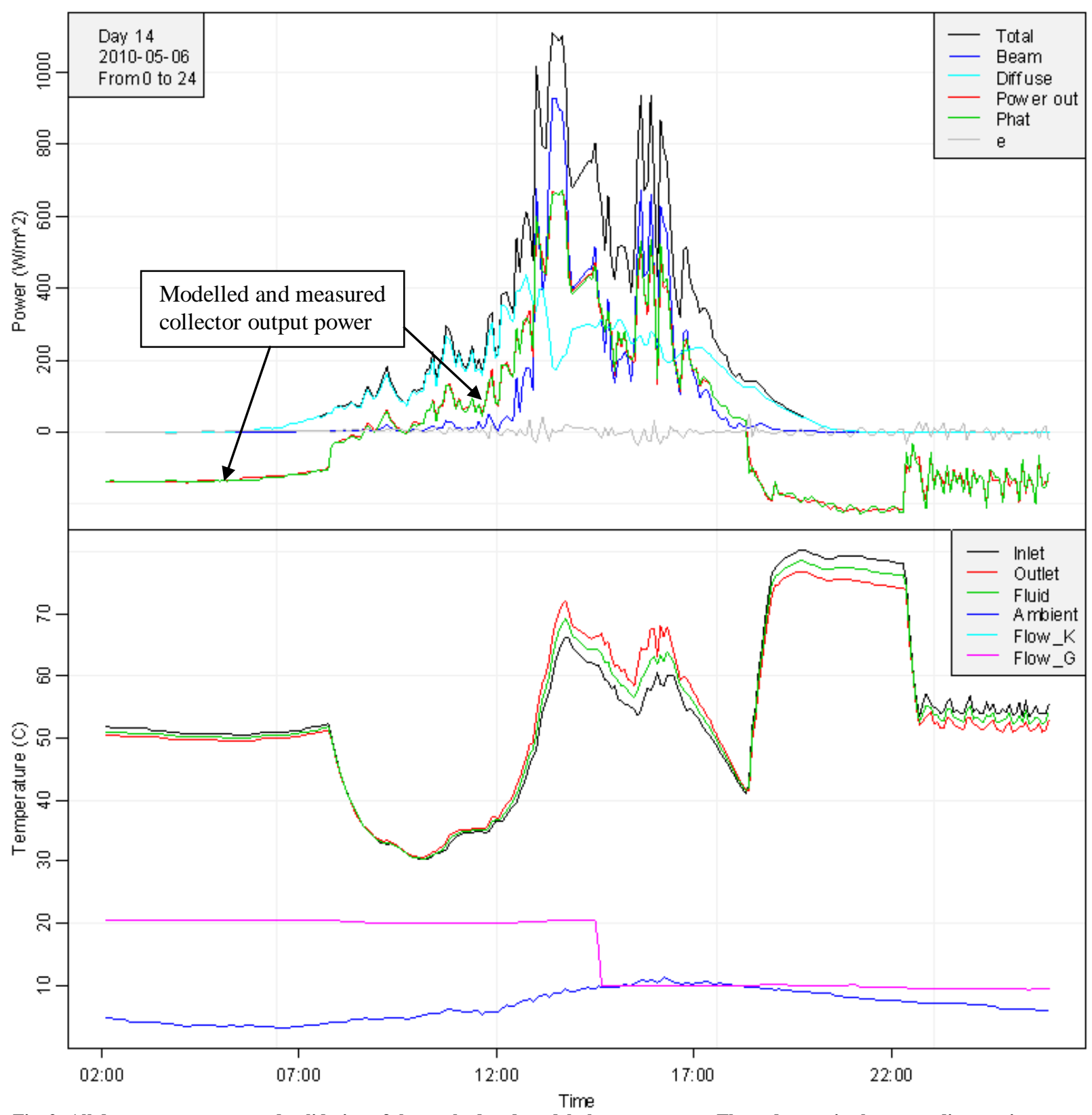

Fig. 2: All day measurements and validation of the method and model plus parameters. The red curve in the upper diagram is measured collector output and the green curve is the model output with the identified parameters for the whole test period 


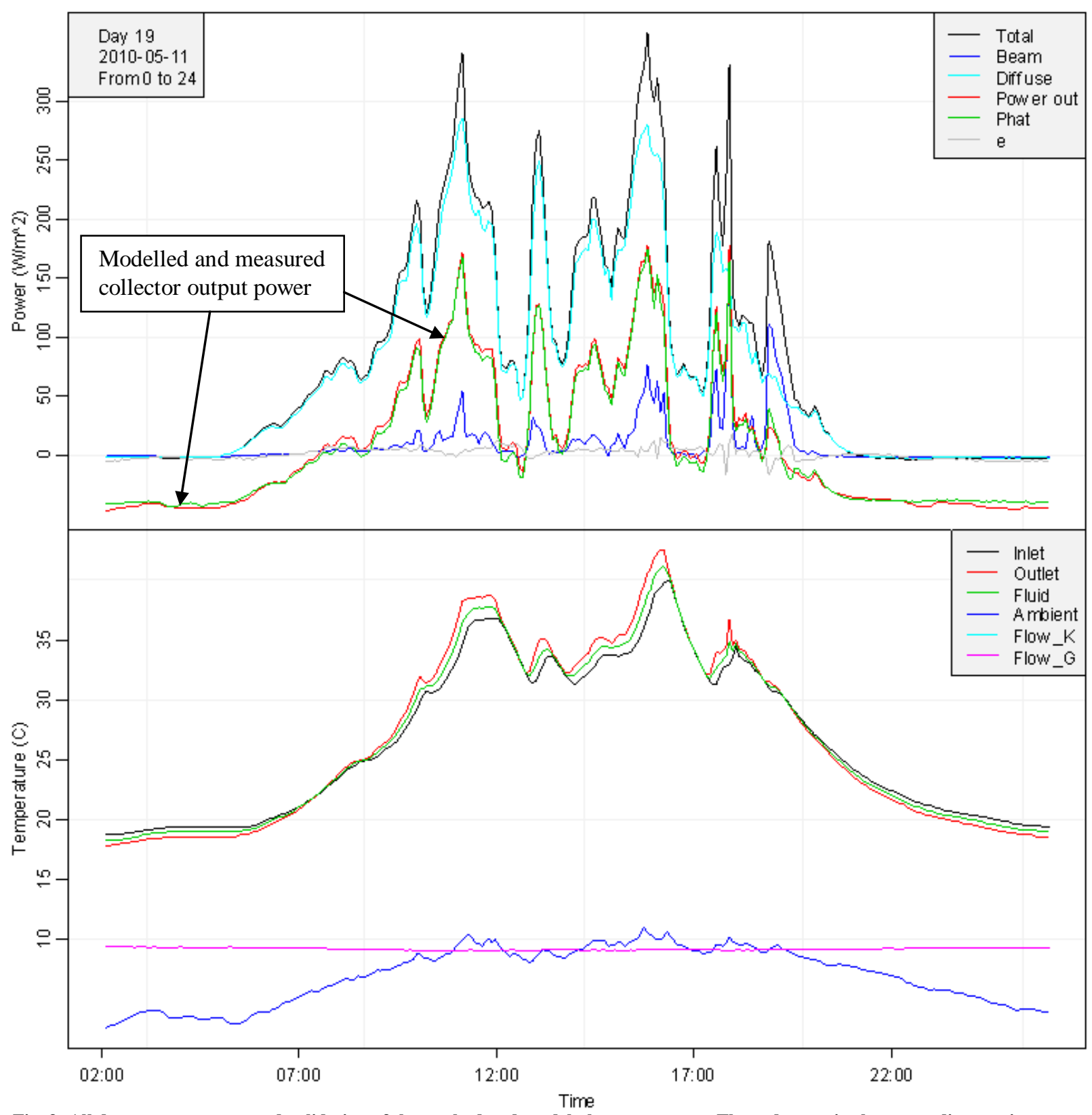

Fig. 3: All day measurements and validation of the method and model plus parameters. The red curve in the upper diagram is measured collector output and the green curve is the model output with the identified parameters for the whole test period 


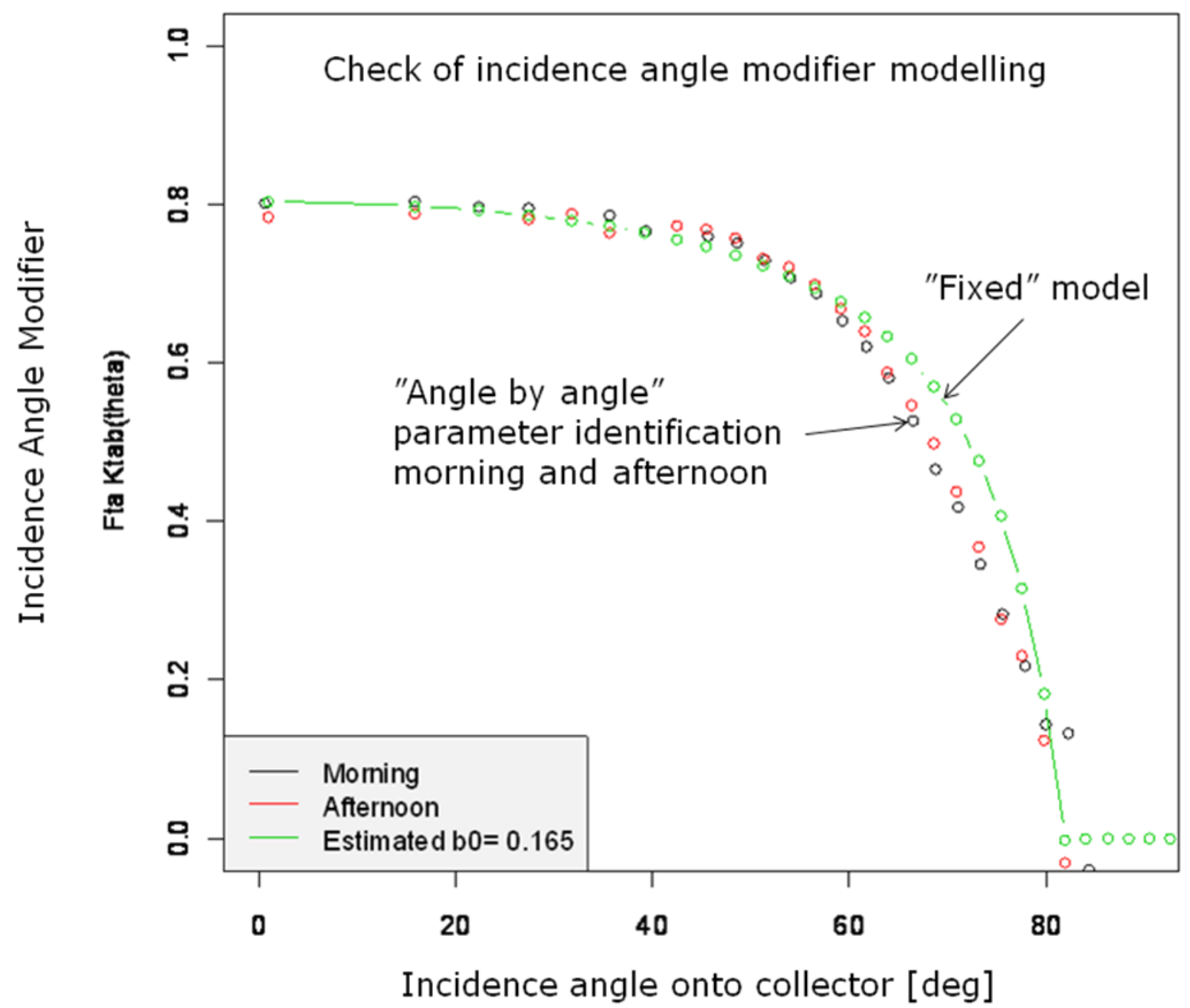

Figure 4. Example of the option to determine the Incidence angle modifier with statistical estimation of non-linear functions without the need of a simple mathematical function (black and red points). Also the separation of morning and afternoon values are shown to give an impression of the reproducibility that the method can give. As a comparison the standard b0 equation is shown.

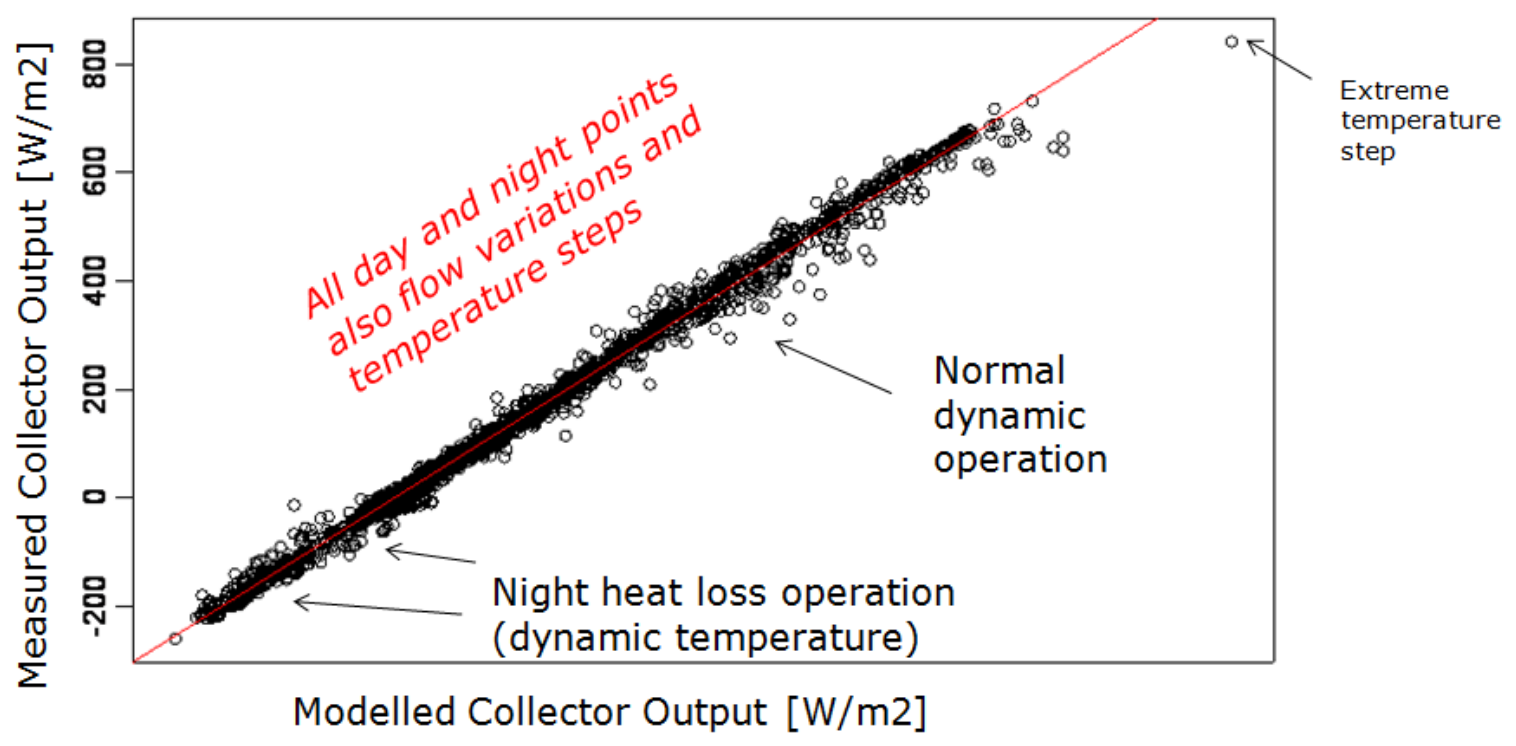

Fig. 5: Model versus measurements including also night heat loss measurements. (Points with negative collector output). 


\section{Discussion and Conclusions}

A first version of a tool has been developed and tested, for all day test data evaluation according to the QDT option in the EN 12975 standard .

The tool contains all steps from import of data to display of final parameters with statistical information.

In the tool the built in model plus parameter validation in the EN12975 QDT method can be applied and displayed. This helps a lot to assure reliable results and especially to find intermittent errors in the test rig, collector samples (like condensation or micro fluid leaks), measurement equipment problems or even unusual occasions like visitors or birds shading the test instruments or collector.

The tool is prepared to deselect obviously wrong data from the analysis and use the advantage with the QDT and MLR method to allow data gaps if needed.

The development has been done with no dedicated project for the work. Therefore further improvements and refinements, as more user friendliness, are possible if a project could be created for this. Also the addition of the EN12975 stationary test SS evaluation could be an option.

\section{References}

Fan, J., Chen, Z., Furbo, S., Perers, B., B., K., 2009. Efficiency and lifetime of solar collectors for solar heating plants.

CEN, European committee for standardization. (2006) "EN 12975-2:2006, Thermal solar systems and components - Collectors - Part 2: Test methods"

Fischer, S., Heidemann, W., Müller-Steinhagen, H., Perers, B., Bergquist, P., Hellstr $\square$ om, B., 2004.

Collector test method under quasi-dynamic conditions according to the European standard en 12975-2. Solar Energy 76 (1-3), 117\{123.

P. Kovacs, B. Perers, U. Pettersson, (2011). Improving the compatibility of collector parameters between Steady state and Quasi dynamic testing for new collector designs. ISES Kassel (this conference)

Perers, B., Kovacs, P., Olsson, M., Persson M., Pettersson, U. (2011). A new tool for standardized collector performance calculations. ISES Solar World Congress, Kassel 2011.

Perers, B., 1993. Dynamic method for solar collector array testing and evaluation with standard database and simulation programs. Solar Energy 50 (6), 517\{526.

Perers, B., 1997. An improved dynamic solar collector test method for determination of non-linear optical and thermal characteristics with multiple regression. Solar Energy 59 (4-6), $163\{178$.

Walletun, H. Eriksson, Leif. Perers, B. Zinko, H. (1986) Vindens inflytande på oglasade solfångare respektive solfångare med konvektionshinder. Studsvik Technical Note ED-86/15.

Perers, B. (1987). Performance testing of Unglased Collectors. Wind and Longwave Radiation Influence IEA Task III. Studsvik 1987. 